\title{
Discrete Roughness Transition for Hypersonic Flight Vehicles
}

\author{
Scott A. Berry ${ }^{*}$ and Thomas J. Horvath ${ }^{\dagger}$ \\ NASA Langley Research Center, Hampton, VA, 23681
}

\begin{abstract}
$\underline{\text { Abstract }}$
The importance of discrete roughness and the correlations developed to predict the onset of boundary layer transition on hypersonic flight vehicles are discussed. The paper is organized by hypersonic vehicle applications characterized in a general sense by the boundary layer: slender with hypersonic conditions at the edge of the boundary layer, moderately blunt with supersonic, and blunt with subsonic. This paper is intended to be a review of recent discrete roughness transition work completed at NASA Langley Research Center in support of agency flight test programs. First, a review is provided of discrete roughness wind tunnel data and the resulting correlations that were developed. Then, results obtained from flight vehicles, in particular the recently flown Hyper-X and Shuttle missions, are discussed and compared to the ground-based correlations.
\end{abstract}

\section{$\underline{\text { Nomenclature }}$}

M Mach number

$\operatorname{Re} \quad$ unit Reynolds number (1/ft.)

$\operatorname{Re}_{\theta} \quad$ momentum thickness Reynolds number

$\mathrm{p}$ pressure (psi)

$\mathrm{T}$ temperature $\left({ }^{\circ} \mathrm{R}\right)$

$\mathrm{x} \quad$ longitudinal distance from the nose (in)

$\mathrm{k}$ roughness element height (in)

j jet penetration height (in)

L model reference length from nose to body-flap hinge line or cavity length (in)

W cavity width (in)

D cavity depth (in)

w cavity diameter (in)

C correlation curve coefficient

$\alpha \quad$ model angle of attack (deg)

$\delta \quad$ boundary layer thickness (in)

$\theta \quad$ momentum thickness (in)

$\mathrm{h}$ heat transfer coefficient $\left(\mathrm{lbm} / \mathrm{ft}^{2}-\mathrm{sec}\right)$

$=\mathrm{q} /\left(\mathrm{H}_{\mathrm{aw}}-\mathrm{H}_{\mathrm{w}}\right)$ where $\mathrm{H}_{\mathrm{aw}}=\mathrm{H}_{\mathrm{t} 2}$

$\mathrm{h}_{\text {Ref }} \quad$ reference coefficient using Fay-Riddell calculation to stagnation point of a sphere

$\mathrm{q} \quad$ heat transfer rate $\left(\mathrm{BTU} / \mathrm{ft}^{2}-\mathrm{sec}\right)$

$\mathrm{H}$ enthalpy (BTU/lbm)

Subscripts

$\infty \quad$ freestream static conditions

e local edge condition

tr transition

dist disturbance

man manifold conditions

* Research Engineer, Aerothermodynamics Branch, Member AIAA.

$\dagger$ Research Engineer, Aerothermodynamics Branch, Associate Fellow AIAA. 


\section{Introduction}

A spacecraft entering Earth's atmosphere initially experiences a heating environment associated with a laminar boundary layer. Eventually, as the atmosphere becomes denser and/or the vehicle surface becomes rougher, the boundary layer becomes turbulent and the heating rate at the surface can increase by a factor four or more. Our ability to understand and predict when this transition to turbulence and higher heating will occur has design implications for the thermal protection system (TPS) needed to protect the vehicle and crew from the harsh reentry conditions. Typically TPS designers try to use a conservative approach such as using an all-turbulent heating profile to select material and size thickness, as was adopted for some of the recent X-vehicle designs and more recently for the Crew Exploration Vehicle (CEV). One advantage of an all-turbulent design approach is that it avoids the issues associated with having to define boundary layer transition criteria. For CEV the all-turbulent approach provides the means to assess initial TPS concepts. While simple from a geometric perspective, the TPS design of the proposed CEV capsule is actually quite complex, due to the many missions and constraints. Entry velocities from lunar return require an ablator TPS to accommodate the combined convective and radiative heating loads. While the ablation process is intended to reduce heating, it will also result in a vehicle that develops a level of distributed surface roughness during entry. In this instance, an all-turbulent design constraint may not necessarily imply a conservative TPS design. Quantifying the effects of an initially laminar ablated surface roughness will be important as the micro and macro imperfections may produce local heating augmentations that are above numerically predicted turbulent smooth wall values.

Surface roughness, as dictated by the state of the TPS, plays an integral role in determining the probable transition onset time during reentry. Most spacecraft designed for reentry have some form of inherent surface roughness, whether in the form of misaligned TPS tiles on the Shuttle Orbiters or, in the case of TPS designed for planetary entry or lunar return, irregularities on the surface formed during entry by spallation and/or ablation due to extremely high surface temperatures. Traditional ceramic-based TPS tiles such as those used on the Orbiters are susceptible to inadvertent roughness such as damage from launch in the form of cavities and/or gap filler protrusions. Inherent roughness is usually of a distributed nature, characteristically small and abundant. Inadvertent roughness is usually of a discrete nature, typically much larger in scale than distributed and isolated or infrequent. For the Space Shuttle Orbiters, the slight misalignments (steps and gaps) between windward acreage TPS tiles represent the background distributed-roughness that in the absence of any large discrete trips will induce boundary layer transition at a Mach number on the order of 8. On two occasions (STS-28 and 73) the Orbiters have experienced early boundary layer transition at Mach numbers nearer to 18 as a result of large protruding gap fillers.

As an example of the perceived importance of discrete roughness transition, much effort has been expended recently, in support of the Shuttle Orbiter Return-to-Flight (RTF) program, on a boundary layer transition (BLT) prediction tool (Ref. 1) that is now part of a suite of engineering tools for assessing damage to the TPS. The group of analytic tools (Ref. 2) was developed for real-time mission support in the event of observed TPS damage, in order to determine if the vehicle is safe to fly as is, or if repair is required. The BLT Tool calculates the expected time of boundary layer transition during entry based on observed damage and/or repair locations and geometries. The program includes a database of computed boundary layer parameters that cover a range of nominal trajectories for entry and utilizes an interpolation tool to extract specific local properties for determining the boundary layer state during the mission trajectory. The BLT Tool is provided as a first step with which to establish the proper heating environment to baseline for the Cavity and Protuberance Heating tools. Calibration of the BLT Tool has been carried out by comparison of predicted transition results to several of the historical high Mach number flight cases. ${ }^{1}$

The present paper provides a discrete roughness data review, both ground-based and flight, which could be utilized to develop correlations for predicting boundary layer transition. The intent of this paper is not to provide an exhaustive literature review of the discrete roughness transition database, but instead provide a compilation of recent results and observations obtained at NASA Langley Research Center (LaRC) appropriate to a range of hypersonic vehicle applications. For clarity within the present paper, the range of applications are classified as slender for low angle-of-attack vehicles such as required for scramjet powered endoatmospheric cruisers (for example, the National Aerospace Plane or NASP), moderately blunt for high angle-of-attack winged reentry vehicles (like the Shuttle Orbiter), or blunt for high drag 
configurations (e.g., heritage Viking class or Apollo derived capsules). Another general distinction between these three classes of vehicles is that the edge Mach numbers over large portions of these vehicles are by and large hypersonic for slender configurations, supersonic for moderately blunt, and subsonic for blunt.

\section{$\underline{\text { Review of Ground-Based Data and Correlations }}$}

With recent advancements in computational capabilities over the past decade, many within the research community strive for the means for modeling the physics of the transition process, thus providing a more robust understanding and transition prediction methodology. However, this truly universal boundary layer prediction methodology (the physics-based model) does not now exist and significant challenges remain to be overcome before this can occur (Ref. 3). In the absence of a first-principles approach to modeling the transition process, the next best thing is to establish empirical correlations using relevant similarity parameters for the transition process and experimental data (either wind tunnel or flight) from appropriate configurations. Past efforts have

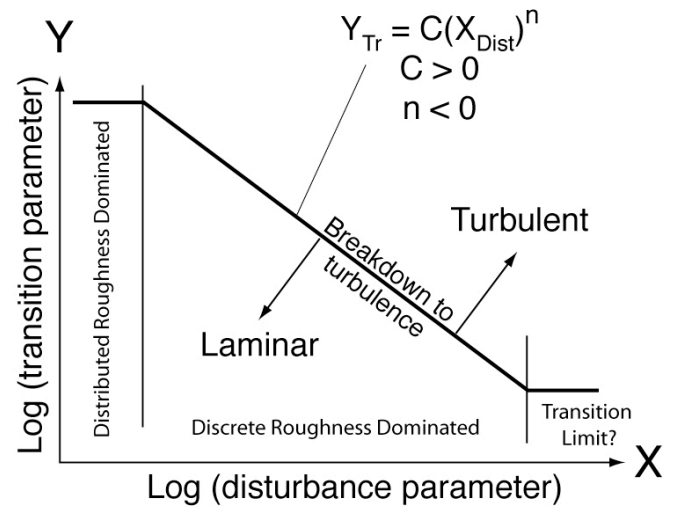

Figure 1. Generalized approach for boundary layer transition correlation development varied from using relatively simple approaches with just a few parameters captured to elaborate correlations using many different parameters. An example of a simple approach that has been shown not to be universally applicable to all situations is the NASP-era criteria $\left(\operatorname{Re}_{\theta}=150 \mathrm{M}_{\mathrm{e}}\right.$ ) for natural transition (in the absence of roughness) on axisymmetric bodies as plotted against ablating ballistic reentry vehicle flight data (see Ref. 4). The NASP criteria actually varies from 150 to 300 based on many considerations not inherently captured by the choice of parameters $\left(\operatorname{Re}_{\theta}\right.$ and $\mathrm{M}_{\mathrm{e}}$ ), such as conical versus planar flows and bluntness effects, and certainly does not capture the effects of ablation. Therefore to develop an empirical transition correlation that is as robust as possible (using a larger combination of parameters), an extensive and comprehensive experimental database from a relevant configuration is required. Reference 5 discusses for the case of roughness-induced transition, correlations can be investigated by comparing boundary layer properties at the roughness site (representing a transition parameter) to some measure of the roughness (a disturbance parameter), see Fig. 1. An ideal correlation is obtained when the results, plotted in log-log coordinates, fall along a straight line with a 45deg slope ( $n=-1$ in Fig. 1). In this case, the transition parameter $\left(Y_{T R}\right)$ multiplied by the disturbance parameter $\left(\mathrm{X}_{\mathrm{DIST}}\right)$ is equal to the curve constant $(\mathrm{C})$. This ideal situation allows the use of an algebraically simple relation to predict the effect of a measured dimension of the roughness on transition using computed boundary layer parameters. Other non-ideal correlations can be utilized, however with the additional complexity of a higher power relationship between the two correlating parameters. Note that the breakdown to turbulence line (the diagonal) identifies the combination of roughness dimension(s) and boundary layer energy required to trip the flow, i.e. below and to the left there is no effect of the roughness, while above and to the right the roughness is large enough to force transition behind the trip. Additionally, a range of applicability of the discrete roughness correlation on either end of the transition curve should be mentioned: at low values of the $\mathrm{X}$-axis when the discrete roughness elements become very small, a plateau is reached which appears a function of the background distributed-roughness to the model or vehicle; while to the right side of the $\mathrm{X}$-axis when the discrete trips become very large, a second plateau is likely that is a function of the minimum energy required to sustain the transition breakdown process in the vortex structure behind the trip (i.e. there may exist a Reynolds number limit below which transition cannot be induced no matter how big the trip is). The change in slope shown in the sketch is meant to imply that the established correlation should not be used outside the appropriate applicability range. A separate and usable distributed correlation might be possible using a different set of correlating parameters.

A number of different roughness types have been compared and contrasted in LaRC facilities over the years, ranging from the distributed to the discrete, see Fig. 2. For distributed, various experiments have 


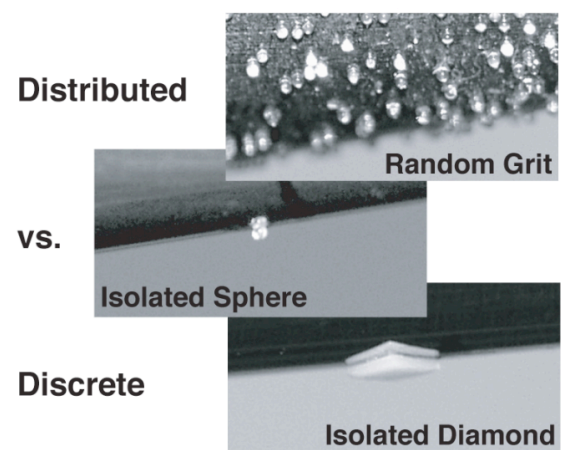

Figure 2a. Comparison of various roughness types as applied to a metallic cone model

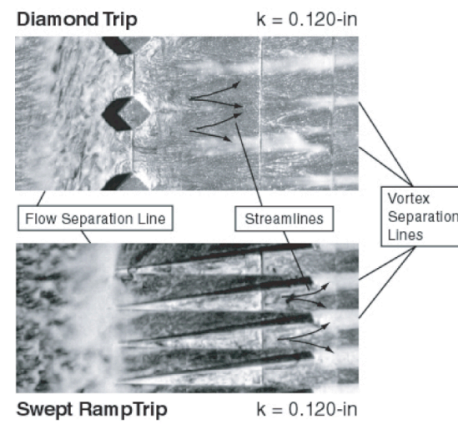

Berry, et. al., NASA TM-2000-210315

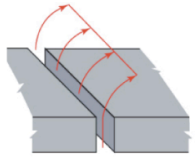

Straight Slot

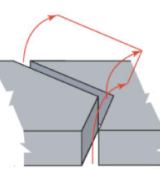

Saw Tooth Slot

Static blowing concepts (plus Holes)

Figure $2 b$. Comparison of various roughness types tested in support of Hyper-X

investigated the effect of randomly distributed grit in the form of precision glass spheres glued to the surface (Fig. 2a), periodic surface waviness representing the bowed metallic TPS panels for X-33, and even the background surface roughness from the phosphor coated ceramic models (phosphor surface roughness can be seen in Fig. 2c). For discrete, spheres have been compared to the diamond configuration (Fig. 2a), then the diamond trip in turn was compared to swept ramp trips for Hyper-X (Fig. 2b) and surface cavities for the Shuttle program (Fig. 2c). The diamond configuration, basically a square protrusion rotated such that the diagonal across opposite corners is aligned with the local flow, provides two forward facing edges angled 45-deg to the oncoming boundary layer, has been shown at LaRC to be a very efficient vortex generator and trip. Additionally, recent studies have been completed (Fig. 2b) where surface blowing through a number of configurations ranging from holes to three-dimensional slots and porous material have shown some promise as trip mechanisms that provide some capability for active control by throttling the mass flow through the system. Blowing through a single hole or sonic orifice has been observed to be analogous to tripping with a sphere, as the flow structures generated by both trips are quite similar. ${ }^{6}$ Perhaps then, blowing through a porous material can

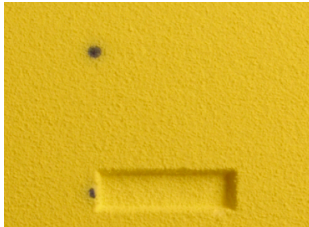

Shoe-box Cavity on Centerline

$+$

Attachment Line

Figure 2c. Comparison of various roughness types tested in support of Shuttle RTF be thought as analogous to distributed roughness. More details about the various forms of roughness tested will be discussed in subsequent sections.

\section{Slender Configurations}

Over the past few decades, NASA has supported many technology maturation programs associated with hypersonic cruise vehicles. Airbreathing propulsion is typically a key component to these programs as a means to reduce the cost of payloads to space or to dramatically increase speed or range. Examples include the NASP and Hyper-X (also known as X-43A). As part of an aerothermodynamic investigation of these programs, an examination of boundary layer effects and roughness-induced transition were also conducted, typically using the LaRC's phosphor thermography system ${ }^{7}$ to obtain global heating images and thus clear indications of the global onset of transition. As noted by the Defense Science Board in 1992, boundary layer transition was one of two critical technical areas in which further development was required before proceeding to full-scale flight test vehicle for NASP. While comprehensive and systematic roughness transition studies were conducted in support of the NASP program, much of those results are not available in the open literature and will not be discussed here. However, some of the lessons learned during NASP were applied to follow-on studies conducted for the Hyper-X program.

The roughness investigations for NASP (and similar follow-on studies) provided some early indication of promise with regard to trip design for hypersonic applications where forced turbulence was required. Conventional wisdom at the time implied trips needed to be much larger than the boundary layer in order to be effective. Hyper-X was one such application where due to the small size of the flight test vehicle, natural transition was not expected to occur prior to the inlet. A laminar boundary layer ingested into the 
engine would be more susceptible to flow separations and thus reduced performance. Boundary layer trip devices for the Hyper-X forebody were therefore experimentally examined, starting in 1997, in several wind tunnels in support of the effort to design the trips needed to ensure a turbulent boundary layer for the scramjet inlet (see Ref. 8). Five different trip configurations were compared in three hypersonic facilities, the LaRC 20-Inch Mach 6 Air and 31-Inch Mach 10 Air tunnels, and in the HYPULSE Reflected Shock Tunnel at the General Applied Sciences Laboratory in Ronkonkoma, NY. The baseline configuration identified from the NASP data was the diamond configuration, which appeared very efficient at promoting transition but with the disadvantage of persistent entrained vorticity in the turbulent region (uniform flow in front of the closed cowl and within the engine was preferred). Heat transfer distributions, utilizing the phosphor thermography and thin-film techniques, shock system details, and surface streamline patterns were measured on a 0.333 -scale model of the Hyper- $X$ forebody. Parametric variations include angles-ofattack of 0-deg, 2-deg, and 4-deg; Reynolds numbers based on model length of 1.2 to 15.4 million; and inlet cowl door simulated in both open and closed positions. Comparisons of transition effectiveness of several candidate trip configurations, including the baseline diamond configuration, led to the selection of a lateral array of swept ramp vortex generators, similar to that shown in Fig. 2b, for the Hyper-X Mach 7 and Mach 10 flight vehicles. Note that while a comprehensive roughness transition database was obtained, mainly for identifying parametric trends of trip shape and height, no attempt was made to develop this data into a correlation of the type shown in Fig. 1 as the corresponding set of computational solutions were not available at the time. An overview of the pre-flight wind tunnel test program can also be found in Refs 9, 10 , and 11.

As a follow-on activity to the Hyper-X trip design effort, active methods such as surface blowing were compared to passive trips using the Hyper-X model. This investigation, Ref. 12, compared several concepts for forcing transition, including passive discrete roughness elements and active mass addition (or blowing), in the 20-Inch Mach 6 Air and the 31-Inch Mach 10 Air Tunnels. Heat transfer distributions obtained via phosphor thermography, shock system details, and surface streamline patterns were measured on a 0.333-scale model of the Hyper-X forebody. The comparisons between the active and passive methods for boundary layer control were conducted at test conditions that nearly match the Hyper-X nominal Mach 7 flight test-point of an angle-of-attack of 2-deg and length Reynolds number of 5.6 million. The primary parametric variation for the previous passive roughness study was a range of trip heights within the calculated boundary layer thickness for several trip concepts. For the active blowing study, the manifold pressure was systematically varied (while monitoring the mass flow) for each configuration to determine the jet penetration height, with schlieren, and transition movement, with the phosphor system, for comparison to the passive results. All the blowing concepts tested, which included various rows of sonic orifices (holes), two- and three-dimensional slots, and random porosity, provided transition onset near the trip location with manifold stagnation pressures on the order of 40 times the model surface static pressure, which is adequate to ensure sonic jets. The present results indicate that the jet penetration height for blowing was roughly half the height required with passive roughness elements for an equivalent amount of transition movement. Figure 3 provides a sample result from this effort comparing the effect of passive and active approaches on the local flowfield for equally effective tripping results (based on phosphor data not shown). The two passive trips on the left are the diamond (Trip 1) and the swept ramp (Trip 2c) selected for the flight vehicles, both protruding approximately the same height as the calculated boundary layer. The two active trips on the right are a triple (and staggered) row of 50 small holes (0.010-in diameter) with 0.125 -in spacing $(\mathrm{H} 4)$ and a 0.005 -in wide saw-tooth slot (S2), both showing the required manifold pressure to be just as effective as the two passive trips. As can be seen in the comparison, the jet penetration height (as identified by the Mach disk) into the boundary layer was smaller than the passive trip height required for transition front movement to the trip location and thus much less intrusive on the boundary layer (no separation induced shock ahead of the trip). A conclusion of Ref. 12 was that

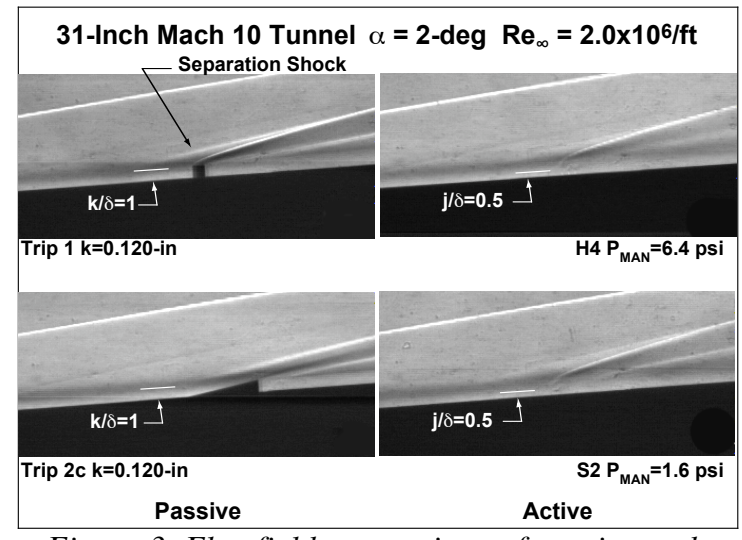

Figure 3. Flowfield comparison of passive and active "effective" trips 
blowing as a discrete roughness element showed some promise, but cautioned that a systems level study would be needed to ensure the added complexity was warranted.

Several basic research experimental studies were initiated in the 20-Inch Mach 6 Air Tunnel to characterize facility noise effects on parametric trends associated with hypersonic slender body transition and to investigate the effect of facility noise on transition criteria developed from data obtained in conventional hypersonic tunnels. In Ref. 13 the relative disturbance environment of the Mach 6 facility (conventional) was deduced from comparisons of smooth wall transition onset locations measured on high-fidelity conical models to results previously obtained in the LaRC Mach 6 Nozzle Test Chamber (NTC) Quiet Tunnel (see Refs 14 - 17), reaching the conclusion that while the conventional Mach 6 tunnel is slightly noisier

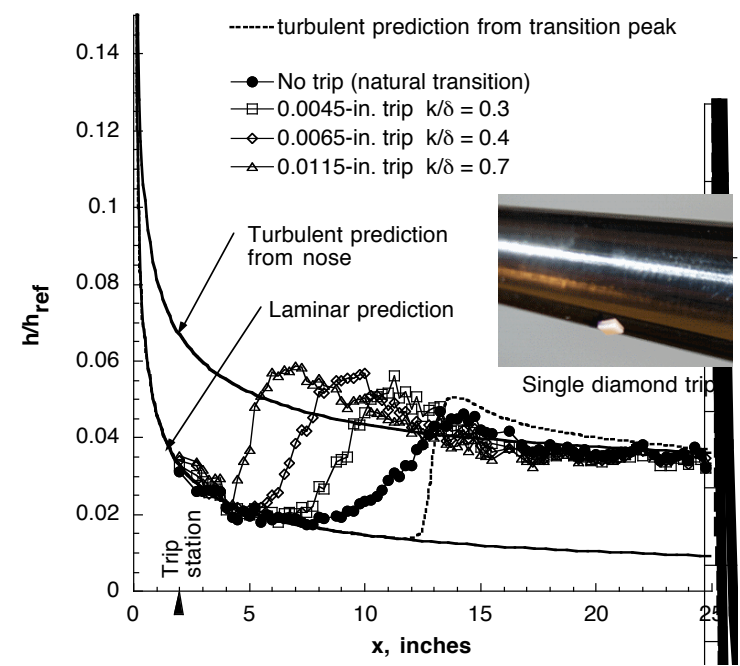

Figure 4. Comparison of measured heating to laminar and turbulent predictions, 5 deg. straight cone, $R_{n}=0.0001$-in, $a=0 \mathrm{deg}, \operatorname{Re}=4.3 \times 10^{6} / \mathrm{ft}$. than the quiet NTC facility, it is not nearly as noisy as NTC in the "noisy" mode. References 18 and 19 document the corresponding RMS free-stream noise levels using several hotwire methods and confirms that the noise levels associated with the 20-In Mach 6 tunnel falls between the NTC levels when quiet and noisy.

As part of the above test series, discrete and distributed surface roughness were utilized to force boundary layer transition to compare against smooth body transition and to insure fully turbulent flows were achieved. Discrete roughness elements investigated were both the diamond configuration and spheres. Multiple trip heights $(\mathrm{k}=0.0045,0.0065,0.0115$-in. $)$ were utilized and applied to the model surface at various axial locations $(\mathrm{x} / \mathrm{L}=0.1,0.2$, and 0.4$)$ for the diamond trip. In addition, discrete and distributed (randomly dispersed) surface roughness in the form of precision glass micro-spheres $(0.0115$-in. diameter) were applied to the model surface near $\mathrm{x} / \mathrm{L}=0.1$. In Fig. 4, natural "smooth" body transition at $\mathrm{Re}=4.3 \times 10^{6} / \mathrm{ft}$ was compared to transition forced with single discrete diamond boundary layer trip. The ratio of trip-to-boundary layer height $(\mathrm{k} / \delta)$ varied from 0.3 to 0.7 . As expected, the larger trip heights were more effective at bringing transition onset closer to the trip location $(x=2-i n)$. Typical of all forms of roughness tested in the study, agreement between the measured smooth wall and the forced turbulent heating with turbulent prediction was generally better than $\pm 5 \%$. Figure 5 provides a comparison of a single discrete diamond trip to a single discrete sphere and randomly distributed spheres. For a fixed height and tunnel condition, the diamond trip was the most effective at moving transition onset forward and closest to the trip station. Note that the diamond also shows a small amount of increased heating in the near wake region behind the trip before onset occurs, likely an indication of strong vortices behind the trips.

\section{Moderately Blunt Configurations}

As part of an on going and evolving NASA effort over the past decade to develop the nextgeneration spacecraft, a number of winged reentry vehicles have also been experimentally examined in LaRC hypersonic facilities. These studies included investigations in support of existing flight vehicles, such as the Space Shuttle, to new development programs in support of proposed Xvehicles. As a fundamental aspect of an aerothermodynamic investigation, examinations of boundary layer effects and roughness-induced transition are also typically conducted. For many

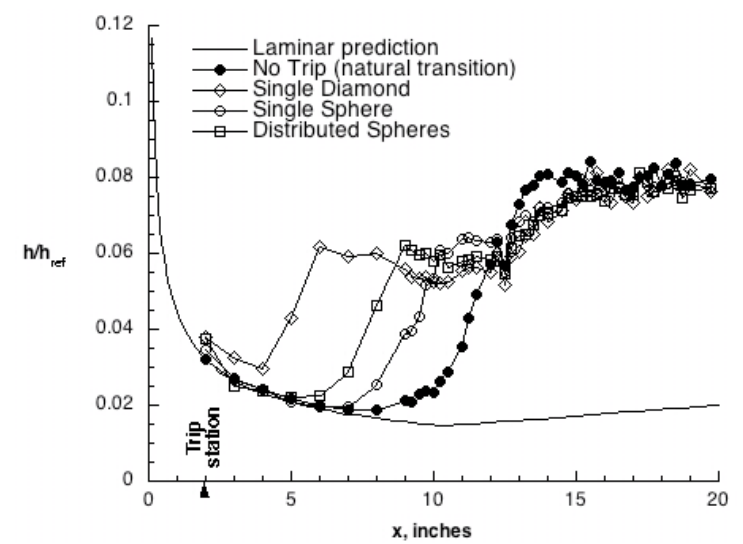

Figure 5. Comparison of different trips, all with same height, 0.0115 -in, on $5 \mathrm{deg}$. flared cone, $R_{n}=0.0001$ in, $a=0$ deg, $\operatorname{Re}=4.4 \times 10^{6} / \mathrm{ft}$. 
of these studies, the phosphor thermography system was used with scaled cast-ceramic models to obtain global heating images and thus clear indications of transition fronts.

An early LaRC investigation into discrete roughness effects on moderately blunt configurations was conducted in support of the asymmetric boundary layer transition (ABLT) working group at Johnson Space Center (JSC). ${ }^{20}$ This effort was established in 1994 to investigate the aerodynamic effect of the boundary layer being laminar on one side of the Orbiter windward surface while turbulent on the other, in order to explain the excessive propellant usage by the reaction control system jets noticed on occasional flights. The effect of an isolated roughness on the windward surface boundary layer of the Shuttle Orbiter was examined in the 20-Inch Mach 6 Tunnel (see Ref. 21). The size and location of discrete trips (here intended to simulate raised or misaligned Shuttle Orbiter Thermal Protection System tiles and protruding gap filler material) was varied in order to systematically examine the response of the boundary layer. Global heat transfer images were obtained, using the phosphor thermography technique, of the windward surface of a $0.75 \%$ scale Orbiter at an angle of attack of 40-deg over a range of Reynolds numbers and were used to infer the status of the boundary layer. Computational predictions were performed using a JSC supplied engineering boundary layer code, BLIMP, ${ }^{22}$ to provide both laminar and turbulent heating levels for comparison to the experimental data and to

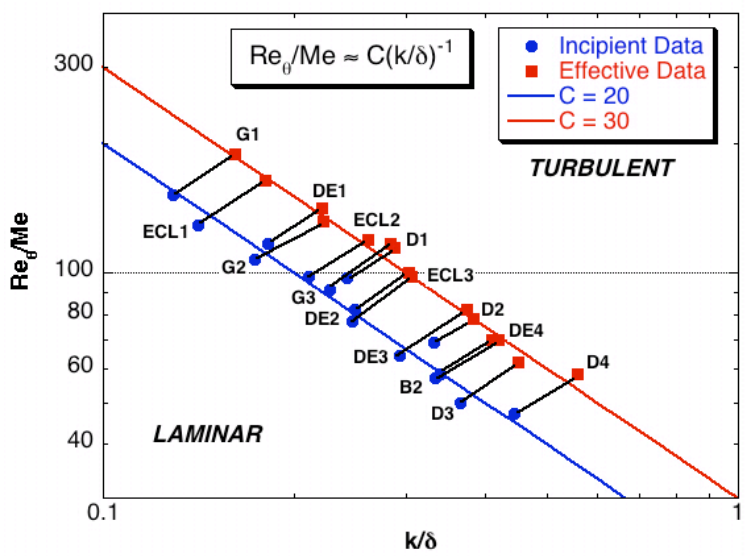

Figure 6. Original Orbiter data based on BLIMP provide flowfield parameters used for investigating boundary layer transition correlations. While a goal of this study was to investigate asymmetric transition effects on aerodynamics, a well-behaved roughnesstransition correlation based on boundary layer edge parameters $\left(\mathrm{Re}_{\theta} / \mathrm{M}_{\mathrm{e}}\right.$ and $\left.\mathrm{k} / \delta\right)$ was identified as a result of this effort using only the centerline data. Figure 6 provides both incipient and effective results (trip designations noted) compared to straight-line curve coefficients of 20 and 30 , respectively. The incipient data represents transition onset far downstream of the trips, while the effective data represents fully turbulent flow as close as possible to the trips.

A similar investigation into boundary layer transition for the X-33 configuration, see Ref. 23, was initiated in 1996. The purpose was to experimentally examine issues affecting boundary layer transition and the effect of transition on the aeroheating characteristics of the X-33. Over a series of wind tunnel entries in the 20-Inch Mach 6 Tunnel, the smooth body transition patterns, the effect of discrete roughness on and off windward centerline, and the effect of distributed bowed panels (wavy surface) were examined. Again, phosphor thermography was used to obtain global surface heating images to assess the state of the boundary layer. Flow visualization techniques, in the form of oil-flow to provide surface streamline information and schlieren to provide shock system details were also used to supplement the heating data. Parametrics included in these tests were the effect of angle of attack ( $\alpha$ of 20deg, 30-deg, and 40-deg), unit Reynolds number (Re between 1 and 8 million/ft), and roughness. The roughness tests included an examination of both discrete and distributed trip mechanisms. The discrete roughness parametrics using the diamond configuration (which included height, size, and location) were included in these tests to provide information to develop roughness transition correlation for the X-33 vehicle and included

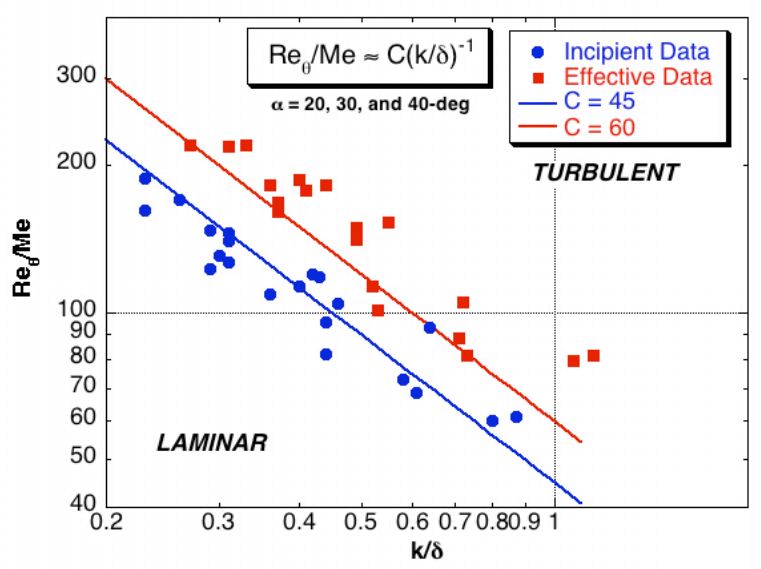

Figure 7. X-33 data based on LATCH results from both the centerline and attachment 
lines of the X-33. The distributed roughness was in the form of a wavy-wall that simulates the expected metallic TPS Panel bowing in flight due to temperature gradients within the panel. The X-33 discrete correlation trends were similar to the previous Shuttle results, but offset, as shown in Fig. 7. While only the centerline results are plotted, the correlative trends were shown in Ref. 23 to apply to the attachment line results as well. The distributed wavy wall results suggested that a peak-to-valley height equivalent to the discrete protrusion height was not nearly as effective at promoting transition. The boundary layer edge properties this time were generated using a LaRC supplied engineering code called LATCH, ${ }^{24}$ and the resulting transition prediction correlations differed from the earlier results by roughly a factor of two. A later investigation into methods for extracting boundary layer edge parameters from computational solutions for comparison to the X-33/LATCH correlation established a different set of correlating curves and a heighten sensitivity to consistency between development and application. ${ }^{25}$

At about the same time a parallel experimental program was established for the X-38 program, a proposed demonstrator of an autonomous orbital test flight vehicle in support of Crew Return Vehicle development for the International Space Station. Integral to the formulation of the X-38 flight data book and the design of the thermal protection system, the aerothermodynamic environment was defined through a synergistic combination of ground based testing and computational fluid dynamics. An overview of the hypersonic aerothermodynamic wind tunnel program conducted at LaRC in support of the X-38 development is provided in Refs 26 and 27. Global and discrete surface heat transfer, force and moment, surface streamline patterns, and shock shapes were obtained on scaled X-38 models in different test gases at Mach 6, 10 and 20. The primary test parametrics include angle of attack from 0 to 50 degs and unit Reynolds numbers from $0.3 \times 10^{6}$ to $16 \times 10^{6} / \mathrm{ft}$. The effects of discrete roughness elements on boundary layer transition were also investigated at Mach 6 for development of a transition correlation for the X-38 vehicle in support of surface roughness criteria for design of the TPS. Using the same LaRC supplied engineering code to provide the boundary layer edge parameters, nearly identical correlative results to X-33 were obtained. ${ }^{26}$

Noting the discrepancy between results using different codes, the original Shuttle data were revisited with the LATCH code to see if better comparison could be obtained (see Ref. 28). The simple approach of correlating roughness transition data utilizing the momentum thickness Reynolds number divided by the edge Mach number $\left(\operatorname{Re}_{\theta} M_{e}\right)$ and the boundary layer trip height divided by the boundary layer thickness $(k / \delta)$ was shown to accurately predict onset of transition when a consistent computational method is used. By replacing the calculated boundary layer parameters originally obtained using the BLIMP code with results from the LATCH code excellent agreement were obtained, see Fig. 8. The primary objective of this reanalysis was to show the critical importance of using a consistent computational method when comparing different transition datasets. The results are plotted in log-log coordinates and show that the effective data fall within $\pm 20 \%$ of a straight-line representation of the power-law curve $\left(\operatorname{Re}_{\theta} / M_{e}\right)(k / \delta)=70$. This result represents the simplest correlation where the data can be fitted by a power-law curve with a -45 degree slope $(n=-1)$ and thus suggests a one to one dependence of transition parameter to the selected disturbance parameter. The selection of a repeatability spread of $\pm 20 \%$ of the curve fit was done to be consistent with the approach of Ref. 5. The key message from Fig. 8 is that when a consistent computational method is used, transition datasets that represent several different moderately blunt configurations at various angles-of-attack can be correlated simply by using properties based on edge conditions. This fairly well behaved and simple correlation appears universally applicable to moderately blunt lifting body configurations in the same class of the Orbiter, as long as a consistent computational approach is used to define and apply the correlation. While the effective data only were plotted here to reduce clutter on the figure, the incipient data could also have been plotted with similar trends (although with a curve constant on the order of half the effective value shown here). Also noted in Ref. 28, the

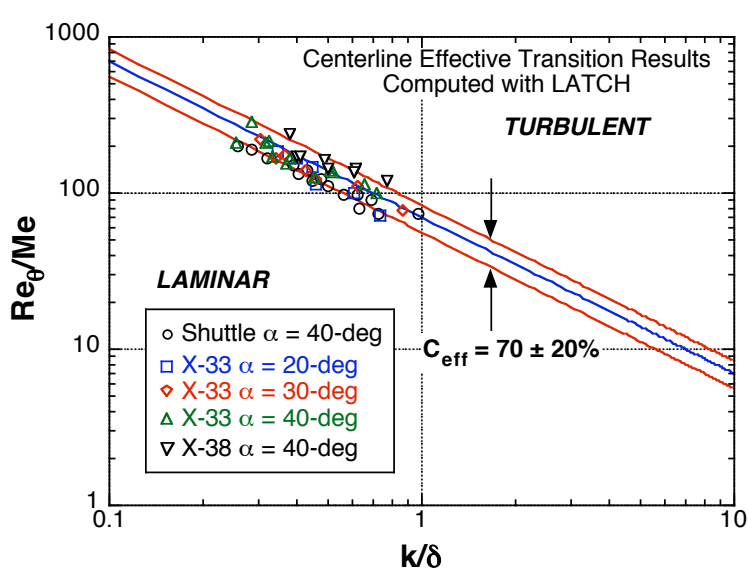

Figure 8. Comparison of effective Orbiter, $X-33$, and $X$-38 data using consistent computational technique 
background distributed roughness associated with a typical phosphor coating on the Orbiter models corresponds to roughly $R e_{\theta} / M_{e}=290$ and $k / \delta$ on the order of 0.05 .

More recently to support the Return to Flight (RTF) effort, a program was established to build on the results reported above, to develop a predictive capability for determining transition onset as part of a suite of analytical tools for examining TPS health during a mission. Based on this relatively simple approach, a useable empirical correlation based on the incipient data (transition onset downstream of the trips to be conservative) was selected. A review of the Orbiter historical flight transition data revealed that while gap fillers have occasionally protruded from between the tiles (leading to earlier transition onset times), the predominant launch-induced damage to the TPS was in the form of gouges, or cavities, to the ceramic tile. Due to concerns about the diminished capacity of damaged tiles to protect the Orbiters, new analysis tools and repair techniques (such as the initial approach of filling the cavities with an ablative material referred to as STA-54 or more recently a tile overlay concept) were developed. For the BLT effort, a new focused experimental program was initiated to provide an experimental database from multiple facilities to establish the transition-onset thresholds due to protuberances (from gap fillers or repairs), cavities (damage sites), and ablation (repairs). The cavity and ablation databases were brand new efforts, as no previous, useable experimental Orbiter data were found, while the protuberance database was an augmentation to the initial effort identified above. All of the experimental results were correlated using a proven computational approach (LATCH), applied to flight in a manner consistent with the development. ${ }^{3}$ Also, critical to the establishment of an uncertainty value in applying a ground-based correlation to flight, an in-depth review of Orbiter flight data was initiated to establish credible flight calibration cases. A complete set of results leading up to the initial version of the BLT Tool were compiled into an informal technical note provided to the Orbiter program and then subsequently in a series of conference papers (Refs. 1, 2, 29, 30, 31, 32). The final correlations adopted in time for the first RTF mission, STS-114, were:

$$
\begin{array}{ll}
\text { For protuberances: } & \mathrm{Re}_{\theta} / \mathrm{M}_{\mathrm{e}} \times \mathrm{k} / \delta=27 \\
\text { For cavities: } & \mathrm{Re}_{\theta} / \mathrm{M}_{\mathrm{e}} \times \mathrm{L} / \delta=900 \\
& \mathrm{Re}_{\theta} / \mathrm{M}_{\mathrm{e}} \times \mathrm{D} / \delta=100
\end{array}
$$

based on damage length

based on damage depth.

A conclusion from the relations above is that a cavity needs to be nearly four times deeper than a protuberance is high for transition onset at the same point along the trajectory, while well over an order of magnitude longer. This trend is consistent with the flight observations mentioned above (also noted in Ref. 33) where almost all the high Mach number transition flights are attributable to gap filler protrusions. The experimental results for ablation (local blowing through a porous plug on the model surface, see Ref. 29) provided an initial assessment that while out-gassing of the repair material might lead to earlier transition onset times, the level of blowing required was over an order magnitude greater than was estimated for the STA-54 material under entry conditions. Also, just prior to the STS-114 mission, the STA-54 repair concept was shelved for large repairs, so no further attempt to provide a useable correlation approach for flight was made.

The RTF BLT protuberance data and correlation developed prior to STS-114 are shown in Fig. 9. The correlation constant of 27 was based on conservatively capturing with over 95\% confidence all the transition onset data from the 20-In Mach 6 Tunnel and 7 historical flight cases with early transition due to gap fillers. It is important to note that the RTF correlations were built using the LATCH engineering code to provide the edge properties for both the wind tunnel and flight data, consistent with the promising approach discussed above. Also, the seven historical flight cases represented our best understanding of the high Mach number transition flight data at the time, recognizing that some uncertainty existed with how well these flights were documented (only post-flight measurements of damage dimensions were available). Considering the time constraints with preparing the BLT Tool for the first RTF flight,

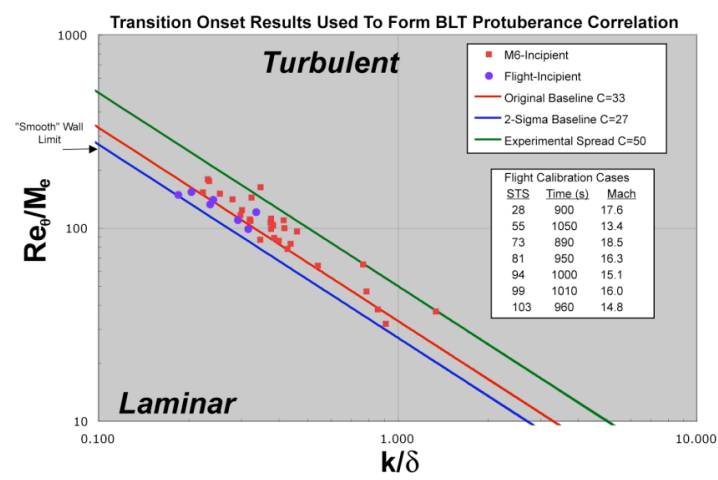

Figure 9. Protuberance correlation developed for use during STS-114 


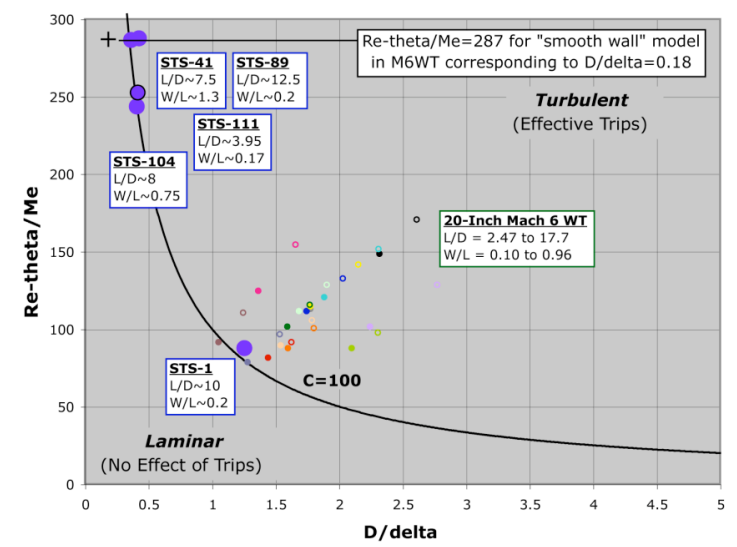

Figure 10a. Cavity correlation based on depth developed for use during STS-114

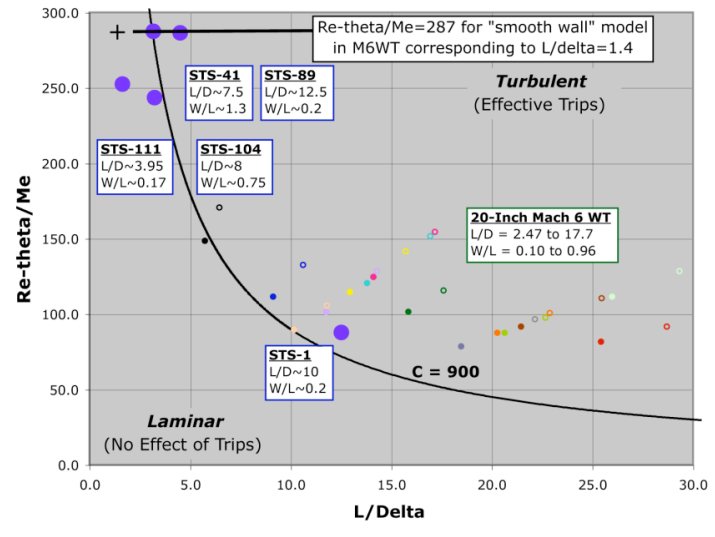

Figure 10b. Cavity correlation based on length developed for use during STS-114

some difficulty was identified with collapsing all the experimental data using the LATCH database. An acceptable correlation was identified and accepted by the program based on using the Mach 6 and flight results only, as shown in Fig. 9. Reasonable and conservative results were expected when the BLT Tool was utilized during the RTF missions (to be discussed further in the flight results section).

The corresponding cavity data and correlations developed prior to STS-114 are shown in Fig. 10. Again under time constraints, a well-behaved correlation for cavities did not initially present itself (where all the data collapsed along a single line). Therefore an approach similar to that used for protuberances was adopted except the height dimension was replaced with either the cavity length or depth. By looking at the cavity based on length or depth separately, an advantage was obtained whereby one could make an assessment of the cavities using only a single dimension (one easily obtainable by the new photographic images captured by the station crew when the Orbiter approaches for docking). Thus the plan for the RTF missions was to initially screen the damage sites using the initial length estimates from the photos and then to use the screening results to advocate for more detailed laser scanning data (which is the only method with which to obtain the depth information for the cavity sites). As with the protuberance correlation, several historical flight calibration cases were used to anchor the Mach 6 ground-based data and, as can be seen in Fig. 10, a much tighter collapse of the flight results are seen in the depth correlation (thus suggesting a BLT assessment based on depth to be more quantitative). While the cavity correlations adopted initially for flight support do not show the classical collapse of onset data along a diagonal line, the selected curve coefficients were thought to be conservative based on the flight calibration cases. The historical cavity cases shown in Fig. 10 were the few that were originally thought to not have protruding gap fillers in the mix. Since the time of this original flight review, a more in-depth look at additional sources of TPS damage information not previously assessed provided a few previously unknown gap fillers that have adjusted the list of calibration cases for cavities (see Ref. 31). Recently, a new cavity correlation has been developed that utilizes the cavity volume (all three characteristic dimensions) to successfully collapse the onset data along a well behaved sloped line that will be brought forward to the program in the near future as an upgrade to the original BLT Tool.

\section{Blunt Configurations}

NASA has been continuously working with blunt body configurations since the dawning of the space era, when the inverse relationship between nose radius and aerodynamic heating was first recognized. Naturally, there was heavy initial emphasis on blunt body investigations during the early manned orbital spacecraft programs of Mercury, Gemini, and Apollo. Since that time, small-scale planetary (for example Viking) and sample return missions have been the primary programs requiring the advantage of bluntness to reduce entry heating. Recent examples include the Genesis ${ }^{34}$ and the Mars Science Laboratory (MSL) ${ }^{35}$ missions, both of which acquired some roughness-induced transition data as part of an experimental aerothermodynamic program.

The Genesis mission successfully collected deep space solar particles and returned them to Earth in 2004 for analysis (although there was a failure with the parachute system which may have compromised 
some of the science return). The TPS for the return capsule was designed with consideration of discrete roughness in the form of cavities on the surface due to structural penetrations required for the launch configuration. The presence of these cavities during entry was a design concern due to the possibility of localized heating augmentation at the downstream cavity wall from flow separation and subsequent reattachment within the cavity. The penetrations also served as a potential disturbance source that could induce boundary layer transition downstream of the cavity site as shown in the phosphor image inset in Fig 11. A wind tunnel heating test in the LaRC 20-Inch Mach 6 Air Tunnel using global phosphor thermography was undertaken to assess the influence of cavity dimension and location on heating augmentation

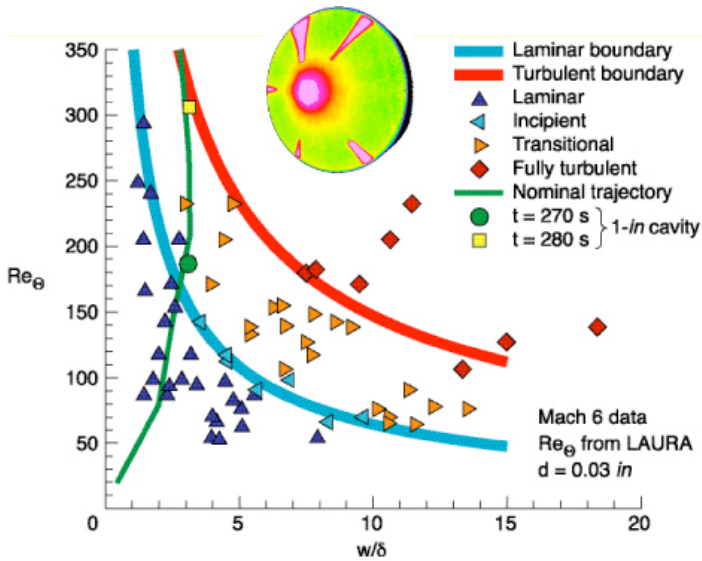

Figure 11. Effect of heatshield cavities on the Genesis sample return capsule aft of the penetrations. For Genesis the cavities were circular with the characteristic dimensions being the diameter (w) or the depth (d), as opposed to the rectangular "shoe-box" cavity shown in Fig. 2b. The global heating images were used to identify cavity effectiveness for promoting boundary layer transition. The laminar, transitional, and turbulent wind tunnel observations were correlated against corresponding CFD predicted local conditions at the cavity site using $\mathrm{Re}_{\theta}$, and the cavity diameter divided by the boundary layer thickness (w/ $/$ ), also shown in Fig. 11. The proposed flight trajectory for locations of peak laminar heating $(\mathrm{t}=270 \mathrm{~s})$ and for peak dynamic pressure $(\mathrm{t}=280 \mathrm{~s})$ were identified in the same trade space and suggested that local flow disturbances aft of the penetrations would exist but fully effective turbulent flow would not be expected until after peak heating. The experimentally derived augmentation factors when coupled with CFD prediction were used to locate and size the diameter of the penetrations at one inch and supported a decision to change the TPS material from a Phenolic Impregnated Carbon Ablator (PICA) to Carbon-Carbon. Images taken of the capsule TPS after impact in Utah, suggest the performance of the heatshield during the hypervelocity/hypersonic phases of entry was optimal. No visual evidence of recession of the cavity (in view of the camera) was observed and surface discoloration patterns on the TPS surface downstream of the penetration site are quite similar to that observed in the wind tunnel.

A similar effort and results were recently obtained for the MSL program (see Ref. 35), which is scheduled for launch in 2009. As with Genesis, the heatshield was initially designed with penetrations to support the launch configuration and cruise vehicle for transit to Mars. Experimental cavity roughness transition data on the 70-deg sphere cone forebody were acquired in the LaRC 20-Inch Mach 6 Air Tunnel using global phosphor thermography. The location and size of the circular cavities were varied along with the model angle of attack and freestream Reynolds number. The correlation methodology adopted for MSL that best collapse the data was similar to Genesis, as shown in Fig. 12. Over an order of magnitude more data points were collected during

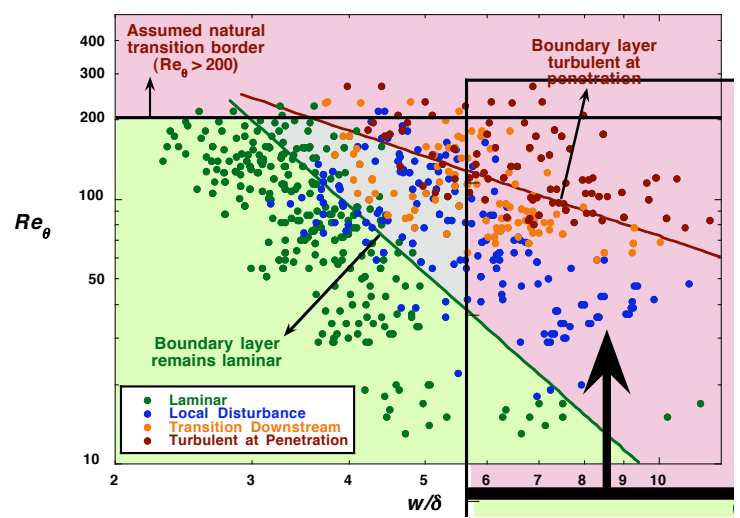

Figure 12. Effect of heatshield cavities on MSL

the MSL test, thus providing higher confidence correlation curves. Note that the MSL program adopted a relatively conservative smooth wall transition onset value of $R e_{\theta}=200$. Below this value the cavities were shown to provide transition onset based on $\operatorname{Re}_{\theta}=3504(w / \delta)^{-2.61}$ and turbulence based on $\operatorname{Re}_{\theta}=725(w / \delta)^{-1}$. Application of these correlations to flight conditions suggested that transition onset would occur well before the peak heating point on the trajectory, thus dictating a vehicle redesign with the launch attachment points being relocated to the aftbody.

The CEV, now also referred to as Orion, is also dealing with similar issues associated with attachment 
hardware on the Orion heatshield. At the present time, several concepts are proposed but all represent some form of protuberance or penetration to the baseline smooth shape. Several tests have been conducted to assess the effects of distributed roughness from PICA ablation and the local aeroheating environments on and downstream of the attachment hardware (not yet published in the open literature). Based upon the present test results, the attachment hardware that represents a protuberance has been redesigned to mechanically retract upon the crew module separation from the service module. As stated in the introduction, CEV is presently adopting an all-turbulent design philosophy for sizing of the TPS.

\section{$\underline{\text { Review of Flight Data }}$}

\section{Hyper-X}

NASA's Hyper-X (X-43A) program has culminated with flight tests of an operational airframeintegrated scramjet propulsion system at hypersonic conditions. Two successful flights have been accomplished, one at Mach 7 and one at Mach 10 as recently discussed in Refs 36, 37, and 38. This program has provided the first opportunity to obtain flight data on an autonomous hypersonic air-breathing propulsion system that is fully integrated with the vehicle airframe, and will validate/calibrate the experimental, numerical, and analytical methods that were used for design and flight performance prediction. Post-flight analysis of the boundary layer state and the effectiveness of the boundary layer trips for both flights are currently on-going as part of this exercise to validate or calibrate design tools.

The following results were obtained on the first successful flight to Mach 7. As predicted using the simple NASP criteria, the classical "smooth wall" correlation methodology $\left(\operatorname{Re}_{\theta} / M_{e}=305\right)$, the upper surface was laminar during the Mach 7 test point. Figure 13 provides upper surface temperature time histories during the first 350 seconds of the Mach 7 flight trajectory from the point of release from the B-52. The three upper surface thermocouples (TC) were evenly spaced along the vehicle centerline starting about midpoint for TC019 and ending near the trailing edge for TC021. Note that by the time the cowl opens and the scramjet is ignited, the entire upper surface appears to be laminar, as indicated by the dramatic temperature decrease that begins

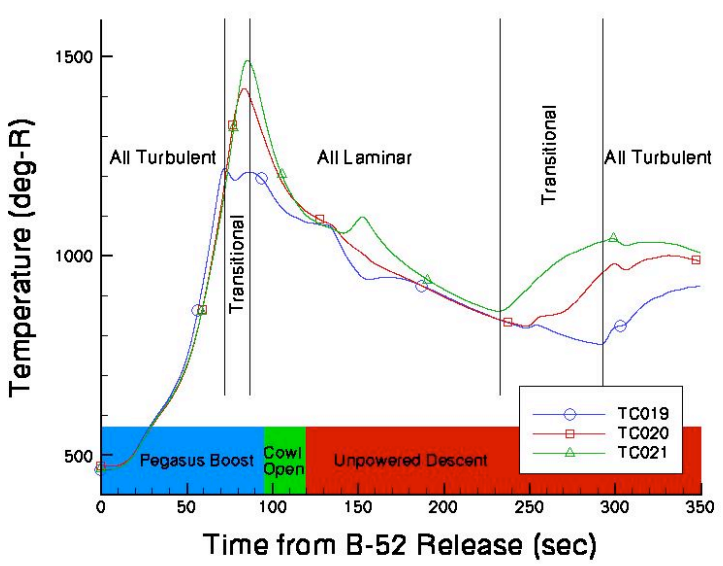

Figure 13. Measured upper surface temperatures during flight 2 (Mach 7) from B-52 drop at about $70 \mathrm{sec}$. Likewise, at about 240 seconds the upper surface boundary layer begins the process of transitioning back to turbulence as the vehicle slows. The pre-flight predictions, using the classical approach mentioned previously, were accurate in estimating these latter transition onset points along the flight trajectory $\left(\operatorname{Re}_{\theta} / \mathrm{M}_{\mathrm{e}}=300 \pm 12\right)$. Thus, in the absence of discrete roughness (trips), transition onset was consistent with the established NASP criteria. However, earlier in the flight, the time of transition ( $\sim 70$ seconds) from turbulent to laminar corresponded to $\mathrm{Re}_{\theta} / \mathrm{M}_{\mathrm{e}}=400$ (it should be noted, however, that these properties are based on laminar predictions). Thus it appears that when using a consistent computational approach the laminar-to-turbulent and turbulent-tolaminar smooth wall transition criteria are not the same, and the X-43A flight data can be used to quantify this hysteresis effect. The lower surface boundary layer trips performed as designed, maintaining turbulent flow for the engine over the entire trajectory. The thermocouple closest to the trips did show a very brief and slight drop in temperature during maneuvering right before the engine test, suggesting a threshold for fully effective tripping at Mach 7 based on roughly $\mathrm{k} / \delta=0.7$ and $\mathrm{Re}_{\theta} / \mathrm{M}_{\mathrm{e}}=110$. If these values were plotted along with the Shuttle, X-33, and X-38 discrete roughness effective data in Fig. 8, the Hyper-X flight-derived correlation would fall within the $20 \%$ scatter shown with a curve coefficient of $\mathrm{C}=77$. The details of the Mach 7 post-flight analysis results are provided in Ref. 39. Although the Mach 10 flight data is still in the process of a detailed analysis, the observed boundary layer trends in the upper and lower surface temperatures are similar to that discussed here for the Mach 7 case. 


\section{$\underline{\text { Shuttle }}$}

Recently the RTF BLT Tool has been used as part of the damage assessment process on STS-114, 121, and 115. For all three flights, large gap filler protrusions have been one of the primary concerns of the damage assessment team, all with predicted transition times earlier than prior historical experience. During STS-114, two large protruding gap fillers were identified in the on-orbit imagery in the forward region of the windward surface. The locations of both of these protrusions were critical, being on either side of centerline such that both wing leading edges would have been influenced by the early-predicted transition onset times. Because of the uncertainty associated with very early transition and the subsequent effect on the wing leading edge heating and structure, the decision was made by the mission management team to remove these two gap fillers with an unprecedented spacewalking repair. Of the remaining protruding gap fillers and damage sites, two appeared to explain the resulting measured transition onset data obtained from the surface thermocouples during reentry, although the transition onset times were nearly nominal (Mach

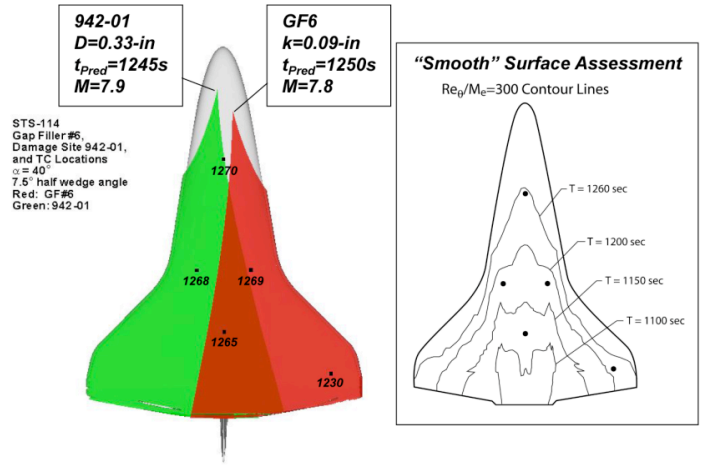

Figure 14. STS-114 transition onset analysis number just below 8), see Fig. 14. Due to the relatively rapid forward movement of transition on the vehicle (on the order of less than 10 seconds), transition was likely due to either one of these discrete trips. For transition due to distributed roughness, the forward movement of the transition front would likely been much slower (on the order of over 100 seconds) based on using a consistent value of $\mathrm{Re}_{\theta} / \mathrm{M}_{\mathrm{e}}$ as a guide. Based on STS-114 flight measurements of transition onset, the BLT Tool provided reasonable but qualitative agreement. Reference 32 provides additional details on the BLT analysis for STS-114. Also, Ref. 40 details a recent study on the local flow around gap fillers (similar to those removed) conducted to gain more insight into the transition process.

Several recommendations had been made to NASA management as a result of the STS-107 accident investigation to improve imaging capability during ascent and descent. As part of RTF, the Shuttle program sponsored an effort to acquire global infrared (IR) measurements during reentry using multiple airborne platforms. An advantage of using aircraft to acquire IR data over ground-based systems ${ }^{41}$ is having the mobility to adjust the location of your IR sensors to accommodate last minute adjustments to the entry profile (wave-offs). This entry imaging activity initiated for STS-114 was viewed by the aeroheating technical community as an opportunity to demonstrate measurement capability incrementally over a series of flights. Should the global imaging technique prove viable, the long-term goal of NASA investigators is to support a flight test that will attempt to provide data to help calibrate and quantify uncertainties with existing or future boundary layer transition prediction methodologies. Due to inclement weather at the primary landing site at NASA Kennedy Space Center, the Orbiter was diverted to Edwards AFB for the STS-114 landing. While no imagery data was collected with two NASA WB-57 aircraft and the Missile Defense Agency's HALO II, the logistics involved with communicating ground track updates and redeploying the aircraft to support one orbit wave-offs was successfully demonstrated.

Prior to the next mission, STS-121, a concerted effort was conducted by the Orbiter program on TPS hardening, whereby large areas of critical gap fillers were removed and replaced to ensure quality bonding within the tiles. Indeed gap filler performance during STS-121 was greatly improved in that no gap fillers in the newly repaired regions came out during this mission. However, there were two gap fillers of interest in the aft windward area that due to time constraints between missions had not been replaced. During the damage assessment for both of these sites, the local TPS and structure were cleared to handle the worst case predicted transition onset times and heating environments, thus the gap fillers were left in place for reentry. One was out on the port wing and was lucky enough to have a surface thermocouple directly downstream of it for establishment of the actual transition onset time during reentry. Based on the actual height as measured on the ground, which was over 0.1-in smaller than the estimates in orbit, predicted transition onset was on the order of Mach 19, but was actually measured to be closer to Mach 17. The prediction was conservative, but maybe overly so as this gap filler was nearly aligned with the local streamlines as opposed to being at a 45-deg angle to the flow like the vortex generators (diamond trips) that the wind 
tunnel database is based on. The RTF BLT Tool does not currently have any method with which to take into account the angle of the local streamlines in relation to the trip. The other gap filler was closer to centerline, just in front of the starboard external tank (ET) door, but did not have any thermocouples in the region for determination of the measured transition onset times.

The STS-121 gap fillers provided a unique opportunity to collect global imagery associated with off nominal Mach number boundary layer transition $(M>8)$. The Shuttle program secured the services of another aircraft, a NAVY P-3 Orion (referred to as Cast Glance) to obtain additional coverage. Cast Glance was successfully deployed

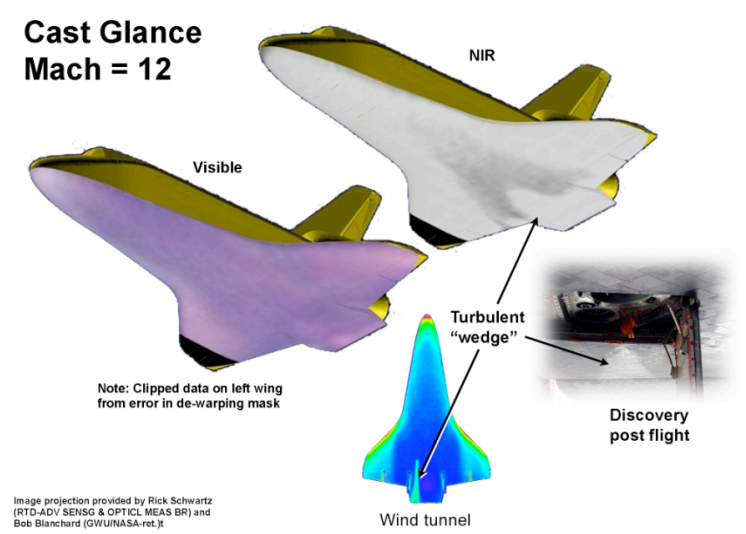

Figure 15. STS-121 near infrared imagery from the Navy's Cast Glance aircraft and stationed under the Orbiter ground track near a point in the reentry where the Mach number was approximately 12 . The other available aircraft (WB-57 and HALO II) were deployed at observation points closer to the nominal transition onset time of Mach 8. The Navy P3-Orion aircraft was able to capture approximately four minutes of imagery. Processed images from closest approach are shown in Fig. 15, both visible and near infrared (NIR), showing the temperature footprint from a turbulent wedge near where the ET door gap filler would have predicted early transition, thus establishing that at least the ET door gap filler had promoted transition prior to Mach 12. The on-orbit prediction for this site was as early as Mach 23 based on the full height of the protrusion. However, due to the quality of the on-orbit photographs, the gap filler was identified to have a number of rips and creases that would likely reduce the height of this trip during entry and the transition onset prediction was thought to be closer to Mach 18. Upon landing, the height of the ET door trip was confirmed to be the smaller height as large portions of the gap filler did in fact rip away during entry. Another piece of circumstantial evidence for early transition for this site was the pattern of discolored tiles identified on the runway that qualitatively matches exactly with the turbulent wedge identified in the NIR image of Fig. 15. The port wing gap filler could not be seen in the images due to over saturation (the bright white regions) of the IR sensors from the higher temperatures on the wing.

The STS-115 mission was the cleanest of the three since the Shuttle program was returned to flight. There were no major cavity sites and only one protrusion of concern. The location for this protrusion was in a similar position to the gap filler from the previous flight, except this time on the port side ET door, and was eventually determined to be a plastic shim stock that would quickly melt away during entry. This time the damage assessment process was completed quickly and the vehicle was cleared for reentry once the station assembly mission was finished. The resulting measured transition onset was nominal, on the order of Mach 6 to 8, a clear indication of lack of damage to the TPS for this flight. Imaging support to STS-115 provided for two aircraft (one WB-57 and Cast Glance). This time Cast Glance was stationed under the ground track at approximately Mach 14 and imagery was collected (both visual and NIR). The STS-115 imagery, Fig. 16 show the incremental improvements made in reducing image saturation (the bright white regions) between missions. Comparison of the NIR intensity images in Figs. 15 and 16 clearly highlight the temperature augmentation just forward of the body flap from the STS-121 protruding gap filler.

A repeating concern for all three flights was the identification of large protrusions with predicted transition onset times earlier than historical evidence. As seen in Fig. 9, the BLT Tool protuberance correlation constant of 27 was calibrated against the seven most credible flight transition cases (STS-28, 55, 73, 81, 94, 99, and

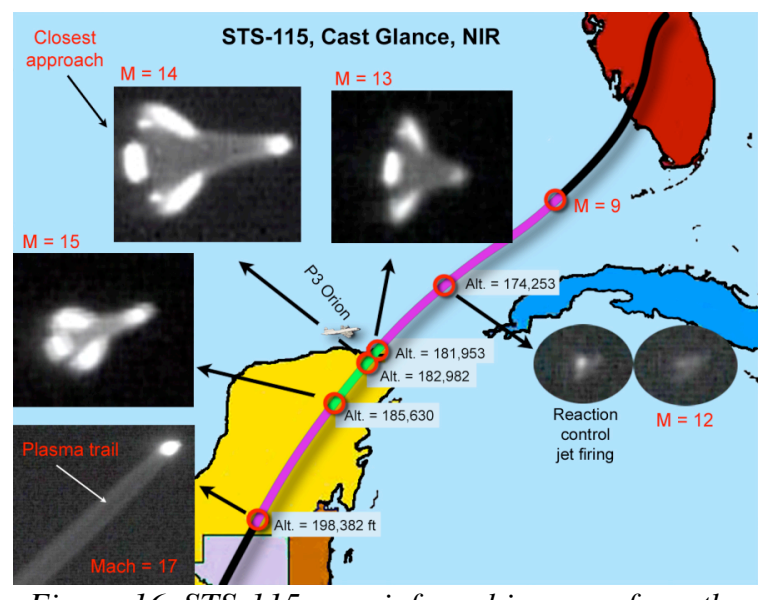

Figure 16. STS-115 near infrared imagery from the Navy's Cast Glance aircraft 
103), with a range in transition Mach numbers of approximately Mach 13 to 18 . Prediction of transition earlier in time, or higher in Mach number, than these calibration cases requires an extrapolation of results outside the range of higher confidence. The uncertainty of the predicted results for transition above Mach 18 is unknown as there is just no data to reliably support any kind of high Mach number transition assessment. For STS-114, because the gap fillers were far forward and had the potential to affect the wing leading edge RCC panels, the uncertainty associated with the very early transition time predictions lead to the decision to remove the gap fillers with a spacewalking repair. For STS-121 and 115, the gap fillers were further aft and the locally affected area could be shown to handle the worst-case transition time predictions with adequate safety margins. Another issue that affects the uncertainty associated with the predictions from the BLT Tool is the issue of gap filler bending. Gaps between the tiles of varying widths require gap fillers of different material types and thickness. The variability of the small fraction of gap fillers that protrude, along with the specific dimensions of the protrusion, on any given flight from the thousands on the windward surface make it nearly impossible to account for bending within the existing BLT prediction framework. A separate analysis on a case-by-case basis of the probability of bending will have to be developed and STS-121 provided an initial attempt at doing so based on the high quality onorbit images that were acquired. Due to the unpredictability of where and whether gap fillers will protrude, or even bend over, on future missions and with the desire to provide as comprehensive and extensive an experimental dataset as possible, a controlled roughness flight test program on the Orbiter has been proposed as a worthwhile endeavor from both scientific and vehicle-risk perspectives.

The program approved protuberance correlation of 27 is based on a $95 \%$ confidence factor that utilizes the Mach 6 ground-based data and flight. In other words, a calibration constant was selected such that the predicted transition onset times would be conservative (prediction earlier than actual) over $95 \%$ of the time. However, as can be seen in Fig. 9, a large portion of the spread in the calibration data can be attributed to the ground-based Mach 6 data. An actual best fit to the flight data provides a curve coefficient of approximately 33 , a $20 \%$ shift in the calibration coefficient. The hope is that additional flight data can provide a rationale for reducing the uncertainty band with regard to how the correlation is applied to flight, which ultimately will feed into reduced likelihood for unnecessary spacewalking repairs.

From the perspective of cavities, five flight cases were initially used to anchor the approved BLT Tool correlations, as shown in Fig. 11. As discussed above, separate correlations based on length and depth were developed using five flight calibration cases (STS-1, 41, 89, 104, and 111) in which it appeared (at the time) that cavities were the primary cause for the early transition event identified by the flight thermocouples. Further in-depth review of the flight data, since the time the tool was approved by the program, has identified previously unknown gap fillers to be a potential influence for some of these five flight cases, thereby causing concerns for their use as cavity calibration cases. Thus, few cavity calibration cases are currently left on the table for use in any future updates to the tool. As such, a controlled and uncontaminated cavity flight experiment is clearly needed to help anchor the ground-based correlations that are currently available. A new cavity volume approach has shown promise, as a way to cleanly collapse all the ground-based data, but how well this correlation works at flight conditions is still to be determined.

Expecting that any proposed flight experiment on the Shuttle be perhaps years away, a more near-term effort called the Hypersonic Boundary Layer Transition (HyBoLT) flight experiment has been proposed and approved. The current launch date is summer of 2007. HyBoLT is the initial payload on a newly developed multi-staged rocket and will acquire data during ascent to over $500 \mathrm{kft}$. Essentially a flying wedge, HyBoLT has two sides with different objectives. Side A is a natural transition experiment, while Side B is discrete roughness experiment designed to support RTF. On Side B, three roughness elements will be flown side-by-side, a cavity in the middle and two protuberances on either side. The instrumentation on both sides will be tailored to optimize the data collection. For instance, on Side B the roughly 100 surface thermocouples will be evenly distributed behind the trips to monitor the movement of transition during the flight. A secondary goal is to acquire local temperatures in and around the trips, and in particular the cavity will be instrumented with sensors on the floor for calibration of the RTF Cavity Heating Tool, which is used during Shuttle missions to assess TPS health. A successful flight this summer will provide critical flight roughness data under controlled and known conditions, but is only considered an interim goal as Shuttle specific data is required at high Mach numbers and enthalpies to assess whether a transition limit (postulated in Fig. 1) does exist that can perhaps explain why there have been no historical flight cases with boundary layer transition earlier than Mach 18. 


\section{Conclusions}

Boundary layer transition due to discrete roughness has a direct impact on the design of hypersonic flight vehicles. Material selection and sizing of the thermal protection system is dependent upon a having a good understanding of when the boundary layer will transition from laminar to turbulent conditions and the resulting impact to the thermal load to the vehicle. Wind tunnel derived roughness criteria have been shown to provide a reliable methodology with which to predict transition behavior for flight vehicles. A review is provided of several recently obtained experimental roughness-induced transition databases and correlation, along with supporting flight results. While some similarities exist between the correlations developed with the different vehicle classifications, inconsistent approaches preclude a direct comparison across platforms. For the Hyper-X program, an experimental program was conducted to design and size discrete tripping elements and the flight results indicate that the trips performed as expected. On the upper surface, natural transition data was obtained which compared favorably with established criteria. For the Shuttle program, ground-based data were utilized to develop empirical roughness-induced transition correlations for use during on-orbit assessment of TPS health. Reasonable but qualitative agreement has thus far been obtained when actual flight measurements have been compared to the BLT Tool predictions. A rational approach for reducing uncertainties with the flight boundary layer prediction methodologies has been suggested through proposed flight experiments.

\section{$\underline{\text { References }}$}

${ }^{1}$ Berry, S. A., Horvath, T. J., Greene, F. A., Kinder, G. R., and Wang, K. C., "Overview of Boundary Layer Transition Research in Support of Orbiter Return To Flight," AIAA-2006-2918, June 2006.

${ }^{2}$ Campbell, C., Anderson, B., Bourland, G., Bouslog, S., Cassady, A., Horvath, T., Berry, S., Gnoffo, P., Wood, B., Reuther, J., Driver, D., Chao, D., and Picetti, D., “Orbiter Return To Flight Entry Aeroheating,” AIAA-2006-2917, June 2006.

${ }^{3}$ Stetson, K. F., “Comments on Hypersonic Boundary-Layer Transition,” Wright Research and Development Center, WRDC-TR-90-3057, Sept. 1990.

${ }^{4}$ Williamson, W. E., “Hypersonic Flight Testing,” AIAA Paper 92-3989, 1992.

${ }^{5}$ Reda, D. C., "Review and Synthesis of Roughness-Dominated Transition Correlations for Reetry Applications," Journal of Spacecraft and Rockets, Vol. 39, No. 2, 2002, pp. 161-167.

${ }^{6}$ Stone, D. R., and Cary, A. M., "Discrete Sonic Jets Used as Boundary-Layer Trips at Mach Numbers of 6 and 8.5," NASA TN D-6802, 1972.

${ }^{7}$ Merski, N. R., "Reduction and Analysis of Phosphor Thermography Data with the IHEAT Software Package," AIAA Paper 98-0712, 1998.

${ }^{8}$ Berry, S. A., Auslender, A, H., Dilley, A. D., and Calleja, J. F., "Hypersonic Boundary Layer Trip Development for Hyper-X,” J. Spacecr. Rockets, Vol. 38, No. 6, pp. 853-864, 2001.

${ }^{9}$ Rausch, V. L., McClinton, C. R., and Crawford, J. L., "Hyper-X: Flight Validation of Hypersonic Airbreathing Technology," ISABE Paper 97-7024, 1997.

${ }^{10}$ Rausch, V. L., McClinton, C. R., and Hicks, J. W., "NASA Scramjet Flights to Breath New Life into Hypersonics," Aerospace America, Vol. 35, No. 7, 1997, pp. 40-46.

${ }^{11}$ McClinton, C. R., Holland, S. D., Rock, K.E., Engelund, W. C., Voland, R.T., Huebner, L. D., and Rogers, R. C., "Hyper-X Wind Tunnel Program," AIAA Paper 98-0553, 1998.

${ }^{12}$ Berry, S. A., Nowak, R. J., and Horvath, T. J., "Boundary Layer Control for Hypersonic Airbreathing Vehicles," AIAA Paper 2004-2246, 2004.

${ }^{13}$ Horvath, T. J., Berry, S. A., Hollis, B. R., Chang C. L., and Singer, B. A., "Boundary Layer Transition on Slender Cones in Conventional and Low Disturbance Mach 6 Wind Tunnels," AIAA Paper 2002-2743, June 2002.

${ }^{14}$ Wilkinson, S. P., "A Review of Hypersonic Boundary-Layer Stability Experiments in a Mach 6 Wind Tunnel," AIAA Paper 97-1819, June 1997.

${ }^{15}$ Blanchard A. E., Lachowicz J. T., and Wilkinson S. P., "NASA Langley Mach 6 Quiet Wind Tunnel Performance," AIAA Journal, Vol. 35, No. 1, January 1997, pp 23-28.

${ }^{16}$ Lachowicz J. T., Chokani N., and Wilkinson S. P., "Boundary-Layer Stability Measurements in a Hypersonic Quiet Tunnel," AIAA Journal, Vol. 34, No. 12, Dec., 1996, pp 2496-2500.

${ }^{17}$ Lachowicz J. T. and Chokani N., "Hypersonic Boundary Layer Stability Experiments in a Quiet Wind Tunnel with Bluntness Effects, NASA CR-198272, January, 1996. 
${ }^{18}$ Chokani, N., Shipluk, A. N., Sidorenko, A. A., and McGinley, C. B., "Comparison Between a Hybrid ConstantCurrent Anemometer and Constant-Voltage Anemometer in Hypersonic Flow," AIAA Paper 2004-2248, June 2004.

${ }^{19}$ Horvath, T., Berry, S., and Merski, N. R., "Hypersonic Boundary/Shear Layer Transition for Blunt to Slender Configurations-A NASA Langley Experimental Perspective," Paper AVT-111-22, Oct 2004.

${ }^{20}$ Bouslog, S. A., An, M. Y., Campbell, C. H., Wang, K. C., and Pelley, R. L., “Orbiter Boundary-Layer Transition Working Group: Analysis and Ground Test Status Report,” NASA Johnson Space Center, JSC-26812, Oct. 1994.

${ }^{21}$ Berry, S. A., Bouslog, S. A., Brauckmann, G. J., and Caram, J. M., "Shuttle Orbiter Experimental Boundary-Layer Transition Results with Isolated Roughness," Journal of Spacecraft and Rockets, Vol. 35, No. 3, 1998, pp. $241-248$.

${ }^{22}$ Murray, A. L. "Further Enhancements of the BLIMP Computer Code and User's Guide," AFWAL-TR-3010, WrightPatterson Air Force Base, OH, June 30, 1988.

${ }^{23}$ Berry, S. A., Horvath, T. J., Hollis, B. R., Thompson, R. A., and Hamilton, H. H., "X-33 Hypersonic Boundary Layer Transition," Journal of Spacecraft and Rockets, Vol. 38, No. 5, 2001, pp. 646-657 (see also AIAA Paper 99-3560, June 1999).

${ }^{24}$ Hamilton, H. H. II, Greene, F. A., DeJarnette, F. R., “Approximate Method for Calculating Heating Rates on ThreeDimensional Vehicles," Journal of Spacecraft and Rockets, Vol. 31, No. 3, 1994, pp. 345-354.

${ }^{25}$ Liechty, D. S., Berry, S. A., Hollis, B. R., and Horvath, T. J., "Comparison of Methods for Determining Boundary Layer Edge Conditions for Transition Correlations," AIAA Paper 2003-3590, June 2003.

${ }^{26}$ Horvath, T. J., Berry, S. A., Merski, N. R., and Fitzgerald, S. M., "X-38 Experimental Aerothermodynamics," Journal of Spacecraft and Rockets, Vol. 41, No. 2, 2004, pp.272-292.

${ }^{27}$ Berry, S. A., Horvath, T. J., Weilmuenster, K. J., Alter, S. J., and Merski, N. R., "X-38 Experimental Aeroheating at Mach 10," Journal of Spacecraft and Rockets, Vol. 41, No. 2, 2004, pp. 293-301.

${ }^{28}$ Berry, S. A., Hamilton, H. H., and Wurster, K. E., "Effect of Computational Method on Discrete Roughness Correlations for Shuttle Orbiter," Journal of Spacecraft and Rockets, Vol. 43, No. 4, 2006, pp. 842-852.

${ }^{29}$ Horvath, T. J., Berry, S. A., Merski, N. R., Berger, K. T., Liechty, D. S., Buck, G. M., and Schneider, S. P., "Shuttle Damage/Repair From the Perspective of Hypersonic Boundary Layer Transition - Experimental Results," AIAA2006-2918, June 2006.

${ }^{30}$ Greene, F. A., and Hamilton, H., "Development of a Boundary Layer Properties Interpolation Tool in Support of Orbiter Return-To-Flight,” AIAA-2006-2920, June 2006.

${ }^{31}$ McGinley, C., Berry, S. A., Kinder, G. R., Barnwell, M., Wang, K. C., and Kirk, B. S., "Review of Orbiter Flight Boundary Layer Transition Data," AIAA-2006-2921, June 2006.

${ }^{32}$ Berry, S. A., Horvath, T. J., Cassady, A. M., Kirk, B. S., Wang, K.C., and Hyatt, A. J., "Boundary Layer Transition Results From STS-114,” AIAA-2006-2922, June 2006.

${ }^{33}$ Bertin, J.J., and Stetson, K.F., "The Effect of Surface Roughness on Shuttle Orbiter Boundary-Layer Transition," Technical Report JSC-27358, NASA Johnson Space Center, January 1996.

${ }^{34}$ Cheatwood, F. M., Merski, N. R., Riley, C. J., and Mitcheltree, R. A., “Aerothermodynamic Environment Definition for the Genesis Sample Return Capsule,” AIAA Paper 2001-2889, June 2001.

${ }^{35}$ Hollis, B, R., and Liechty, D.S., "Boundary Layer Transition Correlations and Aeroheating Predictions for Mars Smart Lander," AIAA Paper 2002-2745, June 2002.

${ }^{36}$ Ferlemann, S.M.; Voland, R.T.; Cabell, K, Whitte, D.; and Ruf, E., "Hyper-X Mach 7 Scramjet Pretest Predictions and Ground to Flight Comparison," AIAA 2005-3322. Presented at 13th International Space Planes and Hypersonic Systems and Technology Conference, Capua, Italy. May 2005.

${ }^{37}$ Engelund, W. C., and Holland, S. D., "Hyper-X / X-43A Aerodynamics: Results from the Mach 7 and Mach 10 Scramjet Flight Tests," Presented at 28th JANNAF Airbreathing Propulsion Subcommittee Meeting, Charleston, SC, June 13-17, 2005.

${ }^{38}$ Voland, R.T and McClinton, C.R., "NASA Hypersonic Overview," Presented at 28th JANNAF Airbreathing Propulsion Subcommittee Meeting. Charleston, SC, June 13-17, 2005.

${ }^{39}$ Berry, S.A., Daryabeigi, K, Auslender, A.H., and Bittner, R.D., "Boundary Layer Transition on X-43A Flight 2," Presented at $28^{\text {th }}$ JANNAF Air-breathing Propulsion Subcommittee Meeting, Charleston, SC, June 13-17, 2005.

${ }^{40}$ Danehy, P., Garcia, A., Borg, S., Dyakonov, A., Berry, S., Wilkes, J., Alderfer, D., "Fluorescence Visualization of Flow Past Triangular and Rectangular Boundary-Layer Trips at Mach 4.2, 6.7 \& 9.8," AIAA-2007-0536, Jan., 2007.

${ }^{41}$ Blanchard, R. C., Anderson, B. P., Welch, S. S., Glass, C. E., Berry, S. A., Merski, N. R., Banks, D. W., Tietjen, A., and Lovern, M., "Shuttle Orbiter Fuselage Global Temperature Measurements from Infrared Images at Hypersonic Speeds," AIAA Paper 2002-4702, Aug. 2002. 